Center for Research on Economic and CREST Working Paper
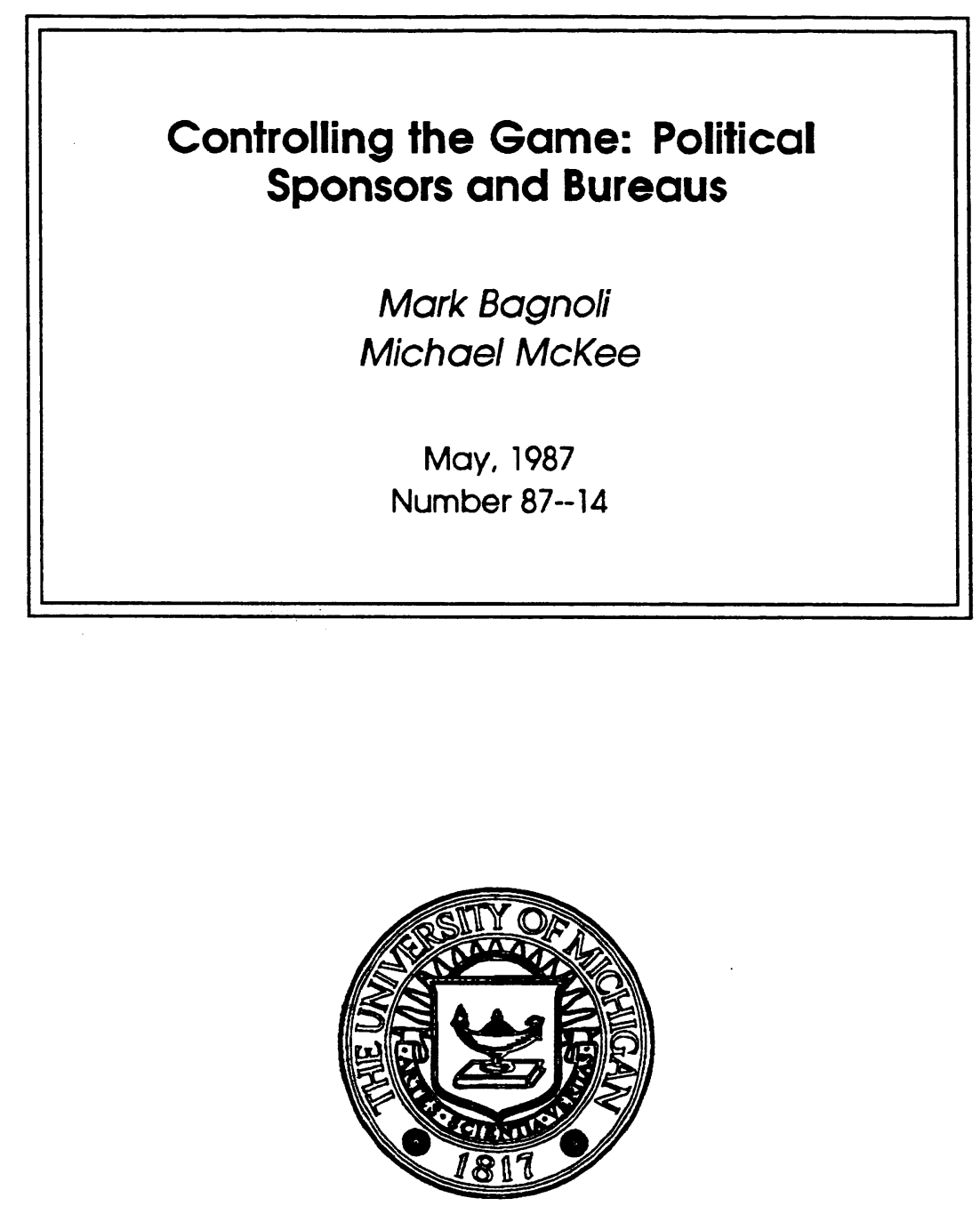

DEPARTMENT OF ECONOMICS University of Michigan Ann Arbor, Michigan 48109 



\title{
Controlling the Game: Political Sponsors and Bureaus
}

\author{
by \\ Mark Bagnoli and \\ University of Michigan \\ Michael McKee
University of Colorado-Boulder
}

Revised: May, 1987

- We would like to thank Michael Hartzmark, Bart Lipman, Ron Wintrobe and an anonymous referee for their assistance. An earlier version of this paper was presented at the 1986 Public Choice Society meeting in Baltimore. 



\section{Introduction}

The predominant view of public sector bureaus, as it appears in the folklore and in much of the economic literature,${ }^{1}$ is that they possess monopoly power which they use to extract the taxpayers' surplus. Since bureaus are organizations that lack a residual claimant, bureaucrats are constrained to take these monopoly rents in the form of non-pecuniary benefits such as shirking on the job, sumptuous furnishings, or other "perks". In other words, public sector bureaus are expected to incur production costs which are above the minimum, technically efficient level. We will refer to the resulting surplus as "fat".

In this paper, we intend to reexamine the foundations of the received theory of bureau behavior. We will provide arguments that suggest the political sponsor is not exploited by the bureau's application of its monopoly power. Instead, we argue that the sponsor may foster competition within or among the bureaus he controls thereby mitigating the bureau's monopoly power. We set our discussion of the sponsor's behavior in the context of a parliamentary system although the results will follow readily for a republican structure. The political sponsor of the bureaus is called a Minister and he is selected by the winning party's leader from the party's successful candidates. In this setting, the Niskanen [1971] thesis and its extensions is that the solution to the bilateral monopoly game played by a bureau and the Minister results in the bureau manipulating the agenda so as to capture all of the rents. ${ }^{2}$

As applied to the Minister's control of the bureau, there are a number of reasons to question Niskanen's prediction. First, since in many instances, the bureau cannot prevent entry it may not possess monopoly power. Second, the bureau may be unable to effectively exercise any monopoly power it may have. This is suggested by the fact that it must take its rents in a non-pecuniary form. Since it is well known that the cash alternative is, in general, preferred, if the Niskanen thesis were correct, one would expect the bureau to manipulate the game so that it could take its rents in cash rather than in a non-pecuniary form. Finally, the traditional view ignores the underlying incentives of the sponsor to curb the excesses of the bureau.

Because the Minister's position is contested within the party, the Minister has private incentives to minimize bureaucratic inefficiencies. These incentives follow from the following institutional facts. One, the position of Minister carries prestige, power and salary (i.e., the position is desirable to the politicians). Two, the leader of the winning party, the Premier, selects the Minister from the set of victorious members of his own party. The Premier has an incentive to select Ministers who are successful and replace Ministers who are not. And three, success takes the form of minimizing bureaucratic excesses so as to keep production costs down.

Bureau excesses are particularly troublesome to the Minister (and the Premier) since there exists an opposition party which has it own incentives to detect and report incidents of such excess. The opposition can take advantage of these incidents by representing them as management (Minister) failures. This is not to say that the bureau will be required to produce at minimum cost,

1 See Borcherding [1983] for a survey.

2 Recently, Breton and Wintrobe [1982, 1986], McKee [1987b] and McKee and Wintrobe [1987] have begun to question the Niskanen thesis as it applies to competition within a bureau. We restrict our attention to the competition that the political sponsor can induce. The reason for this is that internal competition does not preclude the exploitation of the political sponsor by the bureau in the manner described by Niskanen. Such competition merely defines the residual claimant of the bureau rents. 
only that it will be required to reduce political costs. Economic costs can become political costs (lost votes) if they are successfully exploited by the opposition party. The preceding arguments suggest that the Minister has a private incentive to minimize bureaucratic inefficiencies and that the satisfaction of these private incentives should have a major impact on the division of the rents between the bureau and the Minister.

Thus, we argue that the traditional view of the interaction of bureaus and political sponsors is wrong. Bureaus are intrinsically competitive and are made so by the political sponsor who has the incentives to do so. The nature of the competition facing the bureau will depend on the conditions the sponsor can induce. Where there exists a single bureau, the Minister may exploit the internal competition within the bureau by designing the hierarchy such that it extends to the Minister's office itself. ${ }^{3}$ Where the sponsor faces two or more bureaus supplying the same service, self-interested behavior of the part of the sponsor suggests that he will induce competition among the bureaus.

In this paper, we concentrate on the behavior of the political sponsor who attempts to introduce and enforce competition between bureaus. We have argued the political sponsor (Minister) has an incentive to encourage competition between bureaus since he is able to convert such competition into private returns. Further, we will show that this is reflected in observable features of the organization. Our central hypothesis is that the Minister will exploit whatever conditions present themselves to generate competitive forces within the bureaus under his control. Thus, if the historical evolution of the institution has presented the Minister with two or more competing bureaus he will promote a competitive environment by reducing, to the best of his ability, the bureaus' ability to collude.

That is, we hypothesize that the Minister designs the organization of the public sector bureaus to promote efficiency inducing effort on the part of the individual bureaucrats and the bureau itself. Technically, the Minister could always resort to direct control and monitoring of the bureau. This would require that the Minister specify the nature of the output, so there is little room for shirking or opportunistic behavior, and to credibly enforce this specified output. As one would expect, this is likely to be an administratively expensive solution. The sponsor must rely on the use of incentive-compatible or decentralized mechanisms. One such device, if the Minister faces two or more competing bureaus that offer the same service or good, is to induce competition among the bureaus. The Minister may be able to take advantage of their rivalry so as to induce more efficient behavior without direct supervision. In this situation, the Minister's task is to prevent the bureaus from colluding and thereby rendering his efforts ineffective by creating a competitive environment among public sector bureaus.

In section 3 of this paper we formally model this situation as a duopoly game and explore which instruments, under the control of a particular Minister, reduce the potential for collusion between the bureaus. We test, in section 4 , the predictions of our model with data from a particularly useful example: public sector schooling in Ontario, Canada. This is a useful example because there are two parallel public sector education systems which may compete for resources by contesting the market for elementary school enrollment.

We show that the Minister, by manipulating the instruments under his control, has achieved the non-cooperative solution. He has successfully controlled the "game" between the competing bureaus. The Minister's instruments include legislatively specifying the individuals who may choose

3 See McKee [1987b] for an empirical evaluation of this proposition. 
which system to attend and stipulating the shares of revenue each system derives from local taxes and from provincial grants. The result of these decisions is an increase in the systems' incentives to cheat on the potential collusive agreement. The Minister's actions have made collusion by the bureaus more difficult. The Minister's payoff is clearly shown in our empirical work as we show that the result of his actions is a lower level of "fat" in the schools' budgets. Further, we show that the efficiency gains are greatest where the game is most contested. We argue that our propositions are general and that similar results can be found for other instances where the political sponsor may create a competitive environment for the bureaus.

\section{The Institutions}

One can take two approaches to the presentation of a model of an institution. The first approach is to set out the model and describe the assumptions as motivated by the relevant institutional details. The second approach is to provide the institutional setting and then the model so that the reader sees that we have captured the essence of the institution in the model. We adopt the latter approach. The model is presented in the next section of the paper.

We argued above that the position of Minister is awarded on a competitive basis, by noting that not only is the election process competitive, but so is the environment within the winning party. That is, the position of Minister is contested directly at the ballot box and from within the party. Mchee [1987a! has shown that the Minister of Education in Ontario has responded to political competition by allocating proportionately more funding to the growing school system despite its minority status. Here, we will show that the evolution of the position of Minister of Education in Ontario and of the structure of the Ministry has had the effect of increasing the effects of political competition at the ministerial level. We are interested in this in the current context since one effect of this increase is to make the return to inducing efficient behavior in the bureau greater.

From 1846 to 1876 , responsibility for education matters in Ontario rested with Egerton Ryerson who held the position of Chief Inspector. This was an appointed position reporting to the Treasurer and the Prime Minister. It was not until 1876, when Ryerson retired, that a Ministry was established and the education portfolio became an elected position.

Until 1964 the hierarchy within the Ministry had the Deputy Minister reporting to the Chief Director (Superintendent) who reported to the Minister. It is interesting to note that this structure, with a bureaucrat between the Minister and his deputy, was unique and weakened the incentives produced by the political process which we have referred to above. The Minister dealt directly with the chief director (a bureaucrat) rather than a deputy minister. In 1965, at the time that school district consolidation was being advocated by the Ministry, there was a reorganization of the hierarchy which remains basically the same today. ${ }^{4}$ The Chief Director (Superintendent), now part of the Policy and Development Council, has been moved out of the hierarchy and now has an advisory role only. Consequently, the Deputy Minister now has a more direct link to the Minister thereby strengthening the importance of the incentives induced by the political process. ${ }^{5}$ Along with this reorganization, the Ministry also delegated more responsibility to the local school

\footnotetext{
4 It is interesting that the reorganization led to an increase in the importance of the political actors relative to the bureaucrats.

5 For more details, see Fleming [1971b].
} 
boards. They were made responsible for curriculum and other daily activities. In addition, teacher inspection also changed: "As of December 31, 1968 provincial inspection [of teachers] had ceased entirely ..." [Fleming 1971b p. 45]. The responsibility for evaluating teacher productivity passed to the school principal.

All of these changes made the Minister more responsible for the performance of the school system. Then, by the political process, this increased the Minister's incentives to eliminate bureaucratic excesses. At the same time, the delegation of responsibilities for teacher evaluation and curriculum design to the local school boards gave them greater autonomy. Thus, the end result of the reorganization was to shift responsibility to the Minister but, at the same time, to limit his means of directly controlling the local systems. Hence, reliance on a decentralized mechanism was clearly indicated.

In summary, incentives exist to induce the Ontario Minister of Education to seek to reduce bureaucratic excess via a decentralized mechanism. One method is to induce competition among the bureaus. If competition is not fostered, the school boards will "collude" and increase the amount of perquisites consumed by the bureaus. This would result in the bureaus exploiting the Minister and the taxpayers. Thus, the Minister can try to hamper the efforts of the RCSSB and the Public to collude. If the Minister is successful, he will significantly decrease the amount of bureaucratic excess in the system. There are alternative methods such as merely "counting bodies" and to reward the system which increases its enrollment. ${ }^{6}$ Clearly; both schemes, as well as others, could work and the Minister would have the incentive to choose the least costly alternative. An analysis of the differences in the costs of administering these schemes is beyond the scope of this paper. Our purpose is to determine whether the mechanism does "work" rather than find conditions under which it might be the optimal scheme.

In Ontario, the public sector schooling system at the elementary level (Grades $\mathrm{K}$ through 8 ) is divided into local school districts which are organized as counties or large metropolitan areas. Within each school district are two publicly funded school boards. There is a non-denominational board, labelled Public, and a Roman Catholic board labelled Roman Catholic Separate School Board, RCSSB. The unique feature of the public sector schools in Ontario is that many, but not all. parents may send their children to either the Public or the RCSSB in their area. Perhaps more importantly, this choice also determines the share of the local property tax accruing to each of the schools and the assignment of the Provincial grant. The choice is free to Roman Catholics. To qualify as Roman Catholic for the purposes of school choice, one parent must declare him(her)self to be of the Roman Catholic faith. Approximately 35\% of the families in Ontario qualify on this basis. Consequently, parents who qualify as Roman Catholic are permitted to move their children AND their local tax liabilities between the Public and the RCSSB. The net result, to the gaining system, is an increase in revenue from the per pupil from the Provincial grant and the larger share of the local property tax bill.

The definition of "Roman Catholic" for the purposes of schooling choice is controlled by the Minister under the terms of the Education Act [1974] and this is one of the instruments available to the Minister to prevent the bureaus from colluding to increase the amount of "fat" in their budgets. Over the past thirty years the Minister has relaxed the conditions under which a person may declare him(her)self Roman Catholic for the purposes of school choice. During the 1950's a parent was required to furnish a letter from the parish priest testifying that the parent was a

6 In their recent paper, Breton and Wintrobe [1986] analyzed just such a mechanism which was used to foster competition in the extermination of the Jews in Nazi Germany. 
"practicing Roman Catholic". By the early 1970's a parent needed only to sign a civil declaration to that effect. We understand the Minister does not engage in any verification activities. The effect of this relaxation has been to increase the number of parents who may shift their children to the RCSSB. In the next section we show that the effect of this policy action has been to reduce the ability of the bureaus to maintain the collusive outcome.

Each board receives revenues from two main sources: local taxes and Provincial grants. The per pupil grants are set by the Minister to compensate for differentials in the tax bases assigned to the two boards. As we explain in more detail below, the Public tax base is significantly larger than the RCSSB's. This means that the Provincial grant to the RCSSB is larger than the grant to the Public. Regardless, the amount of the grant is set so that either board can provide the basic level of education if their tax rate is equal to that rate which is appropriate, in the Minister's view, for the neediest board. That is, the Minister decides on a tax rate that he feels is appropriate for the neediest board, sets that board's grant so that the board can fund basic education if taxes are levied according to this tax rate, and then the Minister adjusts the grants for the other boards taking account of the fact that they are more prosperous.

Additional or discretionary expenditures by the local school board must be financed from local property taxes which are obviously under the control of the residents of the school district because their approval must be sought. It is possible to conceptually divide school expenditures into "real" educational expenditures and "slack". The taxpayers, by controlling the tax level, can control total expenditures and the Minister can control the division of these expenditures between real and slack by creating a competitive environment. We intend to use the local tax level to measure the slack or "fat" in the bureau's budget. If we control for differences in the local demand for educational services, then differences in the tax levels will reflect differences in the amount of slack.

As we noted above, the property tax base is not assigned uniformly. In particular, the RCSSB has access only to the residential tax base of those who designate support for the RCSSB. The remainder of the tax base (all other residential, all commercial, and all industrial) is assigned to the Public school board. Thus, in any given district, the portion of expenditures financed from provincial grants is much higher for the RCSSB than the Public. ${ }^{7}$ In other words, the Minister chooses which local property taxes, i.e., which local tax bases, are shared by the two boards and which are assigned exclusively to the Public.

The result of the tax and grant assignment is that in the event that a declared Roman Catholic switches to the RCSSB, the Provincial grants adjust so that the total per pupil revenue remains the same for both boards. Thus, the parents cannot reduce their total (local plus provincial) tax obligations by altering the school their children attend. This implies that parents will choose the school system for their children on the basis of the quantity of "real" education expenditure offered by each system. ${ }^{8}$ Thus the actions of the Minister have defined one margin on which the bureaus may compete for pupils: the level of "real" educational expenditure.

The Minister, via the Education Act [1974], has limited the bureaus' discretion in this regard too. In particular, the length of the school day, the length of the school year and the age range of compulsory schooling have been imposed by the Minister. All of these are easily verified by

7 Currently the proportions for the Public are approximately $50 \%$ tax and $50 \%$ grant while the figures for the RCSSB are $20 \%$ and $80 \%$, respectively.

8 In cases where parents have had a choice of public sector schools to send their children it has been reported that the parents incurred considerable search costs in selecting their child(ren)'s school. See Nault and Uchitelle [1982]. 
the Minister and serve to limit some of the margins on which the schools may compete for pupils. However, there is considerable lattitude left to the local boards as to the choice of the level of educational services to provide. Most significant is the possibility of providing smaller classes and/or enriched programs such as music or art. Further, the bureau may increase the amount of services provided to the parents by extending the age range of schooling beyond the Ministermandated compulsory age range. In the case of elementary level schooling this will involve offering schooling to younger children and in Ontario this is manifest as the provision of four year old kindergarten. These increase the availability of resources to the parents and the pupils. Another means of doing this is to provide transportation to the pupils who live more than a short walk to the school since this relieves the parent of the necessity of driving or walking very young children to school. Thus, the Minister has restricted the areas in which the bureaus may compete in an attempt to increase the level of real services available to the parents/voters.

Recall that, the assignment of the tax bases to the school systems is not uniform and the result is that the Provincial per pupil grant is much larger for the RCSSB. We interpret this to be a conscious action on the part of the Minister. When we review the history we find that the Ministry has refused all requests from the RCSSB (or its representatives) to assign the tax revenues of all Roman Catholic's to the RCSSB thereby permitting the Roman Catholic's to choose whether or not to support the RCSSB. ${ }^{9}$ In our presentation of the model it will be shown that the action of the Minister in maintaining the revenue structure increases the likelihood that a collusive agreement between the bureaus to increase budget "fat" will break down.

Further, the consolidation of school districts in 1969 reduced the ability of a small group of parents to change the composition of the school board because the new school boards served a large geographic area. Thus, a parent who was unhappy with his child(ren)'s schooling would be more likely to contemplate a switch of institution (RCSSB to Public or vice versa) as his ability to manipulate the school system originally chosen had been greatly reduced.

Finally, the Minister has precluded the development of mechanisms which would facilitate side payments between the bureaus by limiting the scope of joint provision of educational services. Were the scope not limited, the boards could use this joint provision to facilitate side payments. ${ }^{10}$ Of course, collusive agreements between the school systems cannot be contractual because they cannot be enforced through the courts. This means that any collusive agreement between the school boards must be self-enforcing.

Since the Minister derives benefits from reducing excess, and since fostering competition among the school boards does reduce their excesses, it follows that the Minister will design the institution so as to promote a non-cooperative outcome. If the Public and the RCSSB do collude, they will maximize their joint ability to extract rents from the Minister and indirectly, from the taxpayers. The Minister must overcome this problem if the school systems are to move toward an outcome in which bureaucratic excess is minimized, an outcome in which the welfare of the taxpayers is maximized.

9 One of the reasons that the Ontario school system is such a useful example is that Ontario is unique among the Provinces in retaining the Roman Catholic's freedom of choice. This appears to have been the result of Ryerson's regime. He felt that the demand for Roman Catholic schools would erode as the religious intolerance of the time disappeared and therefore he wanted Roman Catholics to have a free choice of schooling. In Ryerson's view the Public system was the legitimate public sector school system and the RCSSB was to be accepted as a short term device, at best, necessitated by the terms under which Ontario entered Confederation.

10 Obviously, the Minister cannot monitor this joint provision carefully enough to know that the boards are sharing costs as he desires. Hence, by altering the sharing rule, the boards can engage in side payments. 
In the presentation of the model and empirical evidence which follows we show that the Public and RCSSB do compete rather than collude and that this favors the parents/taxpayers as well as the Minister since the bureaus compete by reducing the level of slack in their budgets. We show further, that one can interpret the Minister's actions as structuring the game so that the payoff is very high if one of the school systems defects from the collusive agreement. Our intention is to argue that many policy decisions of the Minister have had the effect of increasing the rivalry between the school systems. These decisions include the Minister's and the court's restrictions on the tax base available to the RCSSB (it includes only the residential property of those who choose to attend the RCSSB) and the definition of the fraction of the market that is contested (the definition of "Roman Catholic" for school purposes).

The other economic agents can be introduced briefly. The local political actors are the school board, made up of elected trustees, and the municipal council, also elected. While the school budget is not voted directly in a referendum process each year, the existence of political competition at the local level suggests we may adopt the median voter model to explain the gross level of schooling expenditure. Parents as well as non-parents may vote in the election of the trustees and the municipal council.

The school bureau is assumed to have an objective function which is increasing in budget "fat" or "perks". While maximization of this slack may be overly simplistic it is clear that the bureau will wish to expand its perks.

To summarize, the local property tax rate is under the control of the residents of the school district. The Provincial grants to both boards in a school district is under the Minister's control. The Minister also controls the assignment of the property tax base. That is, the Minister decides whether the taxes paid on a given property may be assigned by the owner to one of the school boards or not. Lastly, through the definition of who is Roman Catholic, the Minister determines which owners of said property have the right to assign their property taxes to one of the boards. Thus the Minister determines both who has the right to assign property taxes and on which property this right may be applied. 


\section{The Model}

In this section we model the rivalry between the Public and the RCSSB as a non-cooperative game. We intend to use this model to provide testable hypotheses that the Minister actually is trying to promote competition between the school bureaus by taking the actions we described in the previous section. Consequently, our purpose is to examine the actions of the Minister as they affect the payoffs to the bureaus from adopting the collusive strategy. Our argument for focusing on the behavior of the Minister is that he (i.e. the position) has been assigned the property rights to the set of instruments which determine the outcome of the non-cooperative game played by the Public and the RCSSB. The outcome of the game is determined once the Minister has selected the parameters under his control.

Our model of collusion is based upon the seminal work of Friedman [1971]. He appears to be the first to model collusion as the outcome of a non-cooperative game between the players. Many extensions to his work have appeared. They include, Green and Porter [1984], Abreu [1984], and Segerstrom [1985a, 1985b . Our decision to use this structure follow's from the fact that it restricts the analysis to those collusive agreements that can be maintained without written, enforceable contracts. Since the systems are prohibited from using third parties to enforce contracts, the only enforceable collusive agreements are those that are supported as the outcome of a non-cooperative game.

The players are the Public school system and the Roman Catholic school system who play an infinitely repeated game of complete but imperfect information. Each period they observe the previous period's "real" education expenditures of their rival and choose a "real" education expenditure for the current period. "Real" expenditures refer to the cost minimizing level of expenditures incurred in providing a desired level of schooling and is distinct from expenditures on "slack" or costs above this minimum which serve only to increase the utility of the bureau. We model the bureaus' rivalry by recognizing that some parents are permitted to choose which school their children will attend. We assume that this decision is based upon the current period's "real" expenditures by the two school systems which the parents are able to observe. That is, ceteris paribus, parents will choose the system offering the greater level of real expenditure as it should be associated with the system offering the greater level of educational services.

All that remains is to describe the payoff functions for the two systems and to write the model formally. We recognize that modelling the systems as profit maximizes is inappropriate. However, we do believe that the systems' ability to extract perquisites does depend on the residual between revenues and "real" educational expenditures. In other words, the amount of slack in the budget is monotonically related to the quantity of perquisites consumed. Consequently, we will model the systems as attempting to maximize this slack, recognizing that the system does not take its payoff in money but instead spends the money on items it wishes to consume. ${ }^{11}$

Formally, we consider a supergame which is composed of the following stage game repeated indefinitely. The stage game has two players, the Public and the Roman Catholic school systems who choose educational expenditures (henceforth we will describe "real" educational without the

11 For the theory that we are developing, assuming that the systems maximize slack imposes no loss of generality because the systems will maximize slack as a precursor to maximizing their own utility. Unfortunately, the difference between taking one's payoff in money rather than discretionary spending will pose a more serious problem for the empirical testing of our hypothesis. 
adjective since we have called the residual "slack") without knowing their rival's choice in this stage. ${ }^{12}$ The systems compete for students by incurring larger education expenditures. We assume that there are $N$ students in total but only $y N$, for some $y \in(0,1)$, are contested by the systems. Our restriction that $y \in(0,1)$ is imposed because only a subset of all school-aged children can choose to go to the Roman Catholic schools. We simplify the description of the choice of school to attend by assuming that the number of children that attend the Public school, $N_{p}$, as a function of the per pupil expenditures of the Public school, $e_{p}$, and the Roman Catholic school system, $e_{r}$, is

$$
N_{p}=(1-y) N+(1-\alpha) y N+e_{p}-\epsilon_{r} .
$$

Similarly, the number of students attending the RCSSB, $N_{r}$ is

$$
N_{r}=\alpha y N+e_{r}-e_{p}
$$

Note that in the definition of $N_{p}$, the first term, $(1-y) N$ is the number of students who have no choice; they are required to attend Public school. The second term, $(1-\alpha) y N+e_{p}-e_{r}$, is the number of students who are permitted to choose and who choose to attend Public school. Note that implicitly, we have assumed that the Public school receives $(1-\alpha) y N$ of the contested children in the event that the systems choose the same level of per pupil expenditures. Thus, a can be thought of as a parameter that measures the perceived "quality" differences between a Catholic and a Public education. ${ }^{13}$ We assume that parents wish to maximize the level of schooling their children receive and therefore choose their school on the basis of the relative levels of real expenditure. Finally, note that we have assumed that the number of students demanding RCSSB schooling is linear in the difference in the boards' expenditures. This is done to simplify the calculations that follow. Since the outcomes do not result in the enrollment of either of the boards being small, this linear specification is a reasonable approximation. Lastly, we adopt the convention that $e_{i}$ is the educational expenditures in excess of the minimum level of educational expenditures that are mandated by the Minister. This means that choosing zero educational expenditures is equivalent to providing only the minimum level of services mandated by the Minister.

As explained earlier, the Public school system receives the property tax paid on commercial property and its share of the property tax paid on residential property. (Its share being equal to the fraction of the children attending Public schools.) Thus, the systems' payoffs (budgetary slack) from choosing $\epsilon_{p}$ and $e_{r}$ are respectively:

$$
\begin{aligned}
& s_{p}=t_{c} C+\left[(1-\alpha y) N+e_{p}-e_{r}\right]\left[t R+g_{p}-\epsilon_{p}\right] \\
& s_{r}=\left[\alpha y N+e_{r}-\epsilon_{p}\right]\left[t R-g_{r}-\epsilon_{r}\right],
\end{aligned}
$$

where $t_{c}$ is the tax rate on commercial property, $C$ is the assessed value of the commercial property, ${ }^{14}$ $t$ is the tax rate on residential property, $R$ is the PER PUPIL assessed value of the residential property, and $g_{i}$ is the per pupil grant to the $i^{\text {th }}$ system by the provincial government. Since we

12 Recall that the players do know their rival's choices in all previous stages. They also know their rival's costs of inputs, since both systems purchase their inputs in the same markets, and the revenues per pupil for their rival.

13 Under this interpretation, if $\alpha>\frac{1}{2}$ then the Catholic education is perceived to be more desirable than the Public education and vise versa. Note also that any feelings about one system versus the other given equal educational expenditures is captured by $\alpha$.

14 The best way to interpret $C$ is that it is the property base on which the owner is compelled by the Minister to pay taxes to the Public. 
wish to interpret $s_{i}$ as the $i^{\text {th }}$ school system's discretionary expenditures, we must interpret $e_{i}$ as the expenditures necessary to provide the desired level of "real" educational services.

Finally, we must describe the strategies available to the two systems and define our equilibrium concept. Since we wish to examine the Minister's ability to reduce the potential for collusion, Friedman's original model is adequate. Consequently, we assume that the systems may choose classic trigger strategies. A classic trigger strategy specifies an action in the first stage of the game and a conditional action in each subsequent stage. Classic trigger strategies restrict the manner in which the action may be conditioned. The conditioning takes the following form: if your rival has done some action, $A_{1}$, in all previous stages, do $B_{1}$, else do $B_{2}$. The action $B_{2}$ is usually referred to as the punishment action as these strategies are traditionally designed to support collusive agreements. Note that classic trigger strategies involve "harsh" punishment in the sense that each player employs his punishment strategy in every period following the observation that his rival has not done action $A_{1} \cdot{ }^{15}$ Specifically, each board chooses its level of educational expenditure for the current period. Collusion involves reducing this level so that slack is increased and cheating on the collusive outcome involves choosing a higher level of educational expenditure.

We complete the description of the game by specifying our equilibrium concept. Again, to avoid unnecessary complications, we choose to focus on subgame perfect Nash equilibria. Formally, each player $i$ chooses a sequence of functions, trigger strategies, $\sigma_{i}(s)$ for $s=1,2,3, \ldots$, which constitute a subgame perfect Nash equilibrium.

To describe the subgame perfect Nash equilibrium which supports collusion by the school systems, we must compute each system's stage payoff in three distinct situations: when they are colluding, when they are not and when one "cheats" on the collusive agreement. We will do each separately and then construct the equilibrium that supports collusion in the supergame.

We begin by analyzing the Nash equilibrium in the one period game, for it will provide the payoffs to the systems in the event that the collusive arrangement breaks down. This is a relatively straightforward problem in that we seek $\left(e_{p}^{*}, e_{r}^{*}\right)$ which are the Nash equilibrium to the one-shot game. ${ }^{16}$

Lemma 1: The unique Nash equilibrium in the one shot game has

$$
\begin{aligned}
& e_{p}^{*}=t R+\frac{2}{3} g_{p}+\frac{1}{3} g_{r}-\frac{2}{3} N+\frac{1}{3} \alpha y N \\
& e_{r}^{*}=t R+\frac{2}{3} g_{r}+\frac{1}{3} g_{p}-\frac{1}{3} \alpha y N-\frac{1}{3} N .
\end{aligned}
$$

The most direct way to show that these strategies constitute a Nash equilibrium is to show that they satisfy the first order conditions of the system's respective maximization problems. The concavity of the systems' objective functions in their own actions ensures that both first order conditions characterize a maximum, and that this maximum is unique. The first order conditions

15 Most of the refinements of Friedman's work have focused upon relaxing the terms of punishment while still maintaining the collusive agreement. As we will explain later, the boards' optimal trigger strategies are the classic trigger strategies. This explains why Friedman's original analysis is perfectly adequate in this context.

16 For convenience, we assume that the exogenous parameters take on values such that the maximization problem has in interior solution. 
are

$$
\begin{aligned}
& \frac{\partial s_{p}}{\partial e_{p}}=0=-e_{p}+\frac{1}{2}\left[e_{r}+t R+g_{p}-(1-\alpha y) N\right] \\
& \frac{\partial s_{r}}{\partial e_{r}}=0=-e_{r}+\frac{1}{2}\left[e_{p}+t R+g_{r}-\alpha y N\right] .
\end{aligned}
$$

A little arithmetic yields the desired answer and thus our Lemma is proved. Note that the second order conditions for the maximization problems, $\partial^{2} s_{i} / \partial e_{i}^{2}=-1$, are satisfied. Also, for future use, we have the payoffs that result from the one-shot Nash equilibrium as:

$$
\begin{array}{r}
s_{p}^{*} \equiv s_{p}\left(e_{p}^{*}, e_{r}^{*}\right)=t_{c} C+\frac{1}{9}\left[g_{p}-g_{r}+2 N-\alpha y N\right]^{2} \\
s_{r}^{*} \equiv s_{r}\left(e_{p}^{*}, e_{r}^{*}\right)=\frac{1}{9}\left[g_{r}-g_{p}+N+\alpha y N\right]^{2} .
\end{array}
$$

Further, we can derive the first order conditions with respect to the instruments available to the Minister:

$$
\begin{aligned}
& \frac{\partial s_{r}^{*}}{\partial g_{r}}=\frac{2}{9}\left[g_{r}-g_{p}+N+\alpha y N\right]>0 \\
& \frac{\partial s_{r}^{*}}{\partial g_{p}}=\frac{2}{9}\left[g_{r}-g_{p}+N+\alpha y N\right](-1)<0 \\
& \frac{\partial s_{r}^{*}}{\partial y}=\frac{2}{9}\left[g_{r}-g_{p}+N+\alpha y N\right]\left(\frac{1}{3} \alpha N\right)>0
\end{aligned}
$$

and

$$
\begin{aligned}
& \frac{\partial s_{p}^{*}}{\partial g_{p}}=\frac{2}{9}\left[g_{p}-g_{r}+2 N-\alpha y N\right]>0 \\
& \frac{\partial s_{p}^{*}}{\partial g_{r}}=\frac{2}{9}\left[g_{p}-g_{r}+2 N-\alpha y N\right](-1)<0 \\
& \frac{\partial s_{p}^{*}}{\partial y}=\frac{2}{9}\left[g_{p}-g_{r}+2 N-\alpha y N\right]\left(-\frac{1}{3} \alpha N\right)<0 .
\end{aligned}
$$

The second piece of information that we need is the one shot collusive outcome. This may be found by maximizing the sum of the slack in the two school systems with respect to the educational expenditures of the two systems. The collusive maximand is

$$
t_{c} C+\left[(1-\alpha y) N+e_{p}-e_{r}\right]\left[t R+g_{p}-\epsilon_{p}\right]+\left[\alpha y N+e_{r}-e_{p}\right]\left[t R+g_{r}-e_{r}\right]
$$

It is obvious by inspection that this maximization problem has a corner solution in which $\left(e_{p}^{c}, e_{q}^{c}\right)=$ $(0,0)$. For future use,

$$
\begin{aligned}
& s_{p}^{c} \equiv s_{p}\left(e_{p}^{c}, e_{r}^{c}\right)=t_{c} C+(1-\alpha y) N\left(t R+g_{p}\right) \\
& s_{r}^{c} \equiv s_{r}\left(e_{p}^{c}, e_{r}^{c}\right)=\alpha y N\left(t R+g_{r}\right) .
\end{aligned}
$$


Further,

$$
\begin{aligned}
& \frac{\partial s_{r}^{c}}{\partial g_{r}}=\alpha y N>0 \\
& \frac{\partial s_{r}^{c}}{\partial g_{p}}=0 \\
& \frac{\partial s_{r}^{c}}{\partial y}=\alpha N\left(t R+g_{r}\right)>0 .
\end{aligned}
$$

and

$$
\begin{aligned}
& \frac{\partial s_{p}^{c}}{\partial g_{p}}=(1-\alpha y) N>0 \\
& \frac{\partial s_{p}^{c}}{\partial g_{r}}=0 \\
& \frac{\partial s_{p}^{c}}{\partial y}=-\alpha N\left(t R+g_{p}\right)<0 .
\end{aligned}
$$

The final piece of information that we need is the one period payoff to cheating on the collusive agreement. Consider first, the outcome if the Public school system "cheats," i.e., chooses its best expenditure level under the assumption that the Roman Catholic school system chooses $e_{r}^{c}$. The solution involves finding the value of $\epsilon_{p}$ which maximizes

$$
t_{c} C+\left[(1-\alpha y) N+e_{p}\right]\left[t R+g_{p}-\epsilon_{p}\right] \text {. }
$$

Simple calculations show that the solution, $\tilde{\epsilon}_{p}=\frac{1}{2}\left[t R+g_{p}-(1-\alpha y) N\right]$, and that

$$
\tilde{s}_{p} \equiv s_{p}\left(\tilde{\epsilon}_{p}, e_{r}^{c}\right)=t_{c} C+\left[\frac{1}{2}\left(t R+g_{p}+(1-\alpha y) N\right)\right]^{2} \text {. }
$$

The solution when the Roman Catholic school system is the system that "cheats" is found by maximizing

$$
\left[\alpha y N+\epsilon_{r}\right]\left[t R+g_{r}-e_{r}\right] \text {. }
$$

Again, simple calculations give $\tilde{e}_{r}=\frac{1}{2}\left[t R+g_{r}-\alpha y N\right]$, and that ${ }^{17}$

$$
\tilde{s}_{r} \equiv s_{r}\left(e_{p}^{c}, \tilde{e}_{r}\right)=\left[\frac{1}{2}\left(t R+g_{r}+\alpha y N\right)\right]^{2} \text {. }
$$

Together, these imply

$$
\begin{aligned}
& \frac{\partial \tilde{s}_{r}}{\partial g_{r}}=\frac{1}{2}\left[t R+g_{r}-\alpha y N\right]>0 \\
& \frac{\partial \tilde{s}_{r}}{\partial g_{p}}=0 \\
& \frac{\partial \tilde{s}_{r}}{\partial y}=\frac{1}{2}\left[t R+g_{r}-\alpha y N\right] \alpha N>0
\end{aligned}
$$

17 Again, we assume that $\tilde{\epsilon}_{i}>0$. 
and

$$
\begin{aligned}
& \frac{\partial \tilde{s}_{p}}{\partial g_{p}}=\frac{1}{2}\left[t R+g_{p}+(1-\alpha y) N\right]>0 \\
& \frac{\partial \tilde{s}_{p}}{\partial g_{r}}=0 \\
& \frac{\partial \tilde{s}_{p}}{\partial y}=-\frac{1}{2}\left[t R+g_{p}+(1-\alpha y) N\right] \alpha N<0 .
\end{aligned}
$$

With the exception of one detail, we are now able to characterize the conditions under which the equilibrium in the repeated game between the school systems results in the collusive outcome. That detail is the discount rate(s) used by the systems. It is important to recognize that if the discount rate is either 0 or 1 , the model breaks down. If the discount rate is one, the "punishment" is ineffective and collusion is not possible. If the discount rate is zero, the payoffs are not well defined. Thus, we must assume that the discount rate is between zero and one, and for simplicity, we will assume that the systems use the same discount rate, $\beta$. Finally, note that the optimal trigger strategy for the boards is the one that imposes the most severe punishment in the event of a defection from the collusive agreement. This follows from the fact that without uncertainty, there are no "accidental" defections. In a more complete model one could incorporate uncertainty and apply some recent results by Abreu, Pearce and Saccatti [1986] to compute the optimal trigger strategy.

Theorem 1: If $\frac{1}{1-\beta}\left[s_{i}^{c}-s_{i}^{*}\right] \geq \tilde{s}_{i}$ for $i=p, r$, then the following strategies constitute a subgame perfect Nash equilibrium.

$$
\sigma_{i}(t)= \begin{cases}e_{i}^{c} & \text { if } t=1 \\ e_{i}^{c} & \text { if } \forall s<t, \sigma_{j}(s)=e_{j}^{c} \\ e_{i}^{i} & \text { if for some } s<t, \sigma_{j}(s) \neq e_{j}^{c} .\end{cases}
$$

The proof follows immediately from Friedman [1971]. The importance of this theorem is that it allows us to determine, theoretically, what changes in the game make collusion more or less likely. This phrasing is strange when one realizes that the theorem states that if a condition is satisfied, the bureaus will collude and if it is not, they will not. We use the phrase to suggest that there is really some uncertainty, in the Minister's or the researcher's mind, about the true value of particular parameters. Thus, for any given probability distribution on the parameter space, if the Minister, for all parameter values, reduces the difference between $\frac{1}{1-\beta}\left[s_{i}^{c}-s_{i}^{r}\right.$ ! and $\tilde{s}_{i}$ for some $i$, the greater is the probability that the bureaus fail to collude. This is what we mean when we use the phrase "the bureaus are less likely to collude". With this phrasing: collusion is more difficult, the smaller is the difference between $[1 /(1-\beta)]\left[s_{i}^{c}-s_{i}^{i}\right]$ and $\tilde{s}_{i}$ for ONE of the two systems. The reason we emphasize one is that if either system finds it advantageous to cheat on the agreement, the agreement is not self-enforcing. ${ }^{18}$

Consequently, all that remains is to determine how the parameters under the control of the Minister affect the incentives to cheat on the agreement, and then to test our hypotheses. Those

18 It is important to realize that the collusive agreement that we have focused upon is the equivalent of maximizing joint profits. If it is not feasible to support such an agreement, other less profitable agreements can be self-enforcing. This involves choosing the collusive expenditure levels closer to $e_{i}^{*}$. Notice that even if this happens, Ministerial changes that reduce the above difference can be thought of as changing the collusive outcome toward $e_{i}^{x}$, thus reducing the ability of the systems to acquire perquisites. 
parameters under the control of the Minister are $y, g_{p}$, and $g_{r}$, as well as the tax base available to the Roman Catholic school system. Obviously, one would suspect that changing these variables so as to intensify the rivalry between the bureaus would reduce the degree of collusion possible. ${ }^{19}$.

To examine the effects of Ministerial changes, it is useful to define

$$
\Delta_{i}=\frac{1}{1-\beta}\left[s_{i}^{c}-s_{i}^{\times}\right]-\tilde{s}_{i} .
$$

Our problem is to examine how $\Delta_{i}$ changes when the Minister changes the variables under his control.

Our first testable hypothesis follows from an analysis of the effects of changes in $g_{p}$. From above, we know that $\frac{\partial s_{\tau}^{c}}{\partial g_{p}}$ and $\frac{\partial \tilde{s}_{\tau}}{\partial g_{p}}$ are both zero. Therefore;

$$
\frac{\partial \Delta_{r}}{\partial g_{p}}=\frac{1}{1-\beta}\left(-\frac{\partial s_{p}^{*}}{\partial g_{r}}\right)=\frac{1}{1-\beta}\left(\frac{2}{9}\right)\left[g_{r}-g_{p}+N+\alpha y N\right],
$$

which is obviously positive. Note that this immediately implies that a reduction in $g_{p}$ results in the RCSSB becoming less likely to collude. Since we know that collusion is sustained only if both boards are willing: we have our first hypothesis:

$\mathrm{h}_{1}$ : The Minister can increase the likelihood of competition among the boards by reducing $g_{p}$.

Similarly, we know that $\frac{\partial s_{p}^{c}}{\partial g_{r}}$ and $\frac{\partial \tilde{s}_{p}}{\partial g_{r}}$ are both zero. Therefore,

$$
\frac{\partial \Delta_{p}}{\partial g_{r}}=\frac{1}{1-\beta}\left(-\frac{\partial s_{r}^{*}}{\partial g_{p}}\right)=\frac{1}{1-\beta}\left(\frac{2}{9}\right)\left[g_{p}-g_{r} \div 2 N-\alpha y N\right],
$$

whose sign is also positive. As above this implies that a reduction in $g_{r}$ results in the Public board becoming less likely to collude. This yields our second hypothesis:

$\mathrm{h}_{2}$ : The Minister can increase the likelihood of competition among the boards by reducing $g_{r}$.

The intuition behind these results is reasonably straightforward. Consider an decrease in $g_{r}$ for example. This decrease reduces the benefits of collusion to the RCSSB because it induces the Public to decrease expenditures in the non-cooperative equilibrium. This decrease is partially met by a decrease in the RCSSB's expenditures which increases the amount of slack available in the non-cooperative equilibrium. Thus, the penalty for "cheating" on the collusive agreement declines as a result of the decrease in $g_{p}$. This, in turn, makes it more likely that the RCSSB cheats on the collusive agreement.

Note that in both cases, the magnitude of the effect of this change is larger the larger is $g_{r}-g_{p}$. Analogously, the magnitude of the effect of a change in $g_{r}$ is larger the larger is $g_{p}-g_{r}$. Thus, we

19 As our focus is on the behavior of the Minister we do not explicitly compute the consequences of a change in $t$. (:learly, this is under the control of the school district's residents and could be used to promote competition tou. It is straightforward to show that our model suggests that increases in $t$ reduce the likelihood of collusion. 
see that the Minister has an incentive to make the difference between the grants large. Our model does not explain which is larger but provides an explanation for why they do differ as we saw in the previous section. This result also helps to explain the Minister's resistance to changes in the regime despite considerable pressure to do so.

Since the difference in the per pupil grants is nearly constant across all school districts one is unable to satisfactorily test hypotheses 1 and 2 . On the other hand the fraction of Roman Catholics (the contested part of the market) does vary considerably across districts thus our main hypothesis for empirical evaluation is obtained by considering the effects of a change in $y$, the fraction of people who may choose which school to attend. We will explicitly compute $\frac{\partial \Delta_{p}}{\partial y}$ from the derivatives computed earlier.

$$
\frac{\partial \Delta_{p}}{\partial y}=\frac{1}{1-\beta}\left[\frac{-\alpha N}{3}\left(t R+g_{p}+2 e_{p}^{*}\right)\right]+\alpha N\left(t R+g_{p}-\tilde{\epsilon}_{p}\right) .
$$

For this to be negative,

$$
\frac{1}{1-\beta}\left[\frac{-\alpha N}{3}\left(t R+g_{p}+2 e_{p}^{*}\right)\right]+\alpha N\left(t R+g_{p}-\tilde{e}_{p}\right)<0
$$

A little arithmetic shows that this is equivalent to

$$
\beta>\frac{2}{3}-\frac{2 e_{p}^{x}-\tilde{e}_{p}}{t R+g_{p}-\tilde{\epsilon}_{p}} .
$$

Since $\epsilon_{p}^{*}>\tilde{e}_{p}$ the above inequality is certainly satisfied whenever

$$
\beta>\frac{2}{3} \text {. }
$$

By the definition of $\beta, \beta=\frac{1}{1+r}$ where $r$ is the real interest rate. Thus, a sufficient condition for an increase in $y$ to decrease the likelihood of collusion may be rewritten as

$$
\beta>\frac{2}{3} \Rightarrow \frac{1}{2}>r \text {. }
$$

In other words, a sufficient condition for an increase in the fraction of the students who may choose which school to attend to decrease the likelihood of collusion is that the real interest rate not exceed $50 \%$. It seems reasonable to believe that this condition is satisfied. Thus, we have our final hypothesis:

$\mathrm{h}_{3}$ : The Minister can increase the likelihood of competition by increasing the fraction of students that may choose which school to attend. 


\section{Empirical Hypotheses and Tests}

In this section of the paper we describe and test a set of specific hypotheses derived from the model. Recall that our central hypothesis is that the Minister chooses an environment (designs a mechanism) to discourage collusion. Also, recall that the Minister's instruments are the assignment of tax bases and grants to finance schooling, the legal definition of who has the right to choose between the school systems (who qualifies as Roman Catholic for the purposes of school choice), and the definition of the margins for competition by mandating a minimum level of schooling. If he has chosen his instruments as we claim, the result will be apparent in observable features of the organization. It is these features that form the basis of our empirical tests.

In section 2 we noted that the public sector school system in Ontario is organized into local school boards or districts which have substantial autonomy over their activities. The local school boards have some control over their level of expenditures. We suggested that collusion would take the form of increasing the volume of bureaucratic excesses since the systems are unable to take the extracted rents in a pecuniary form. Therefore, we expect to see this reflected in additional slack and/or reduced educational expenditures. ${ }^{20}$

We have cross-sectional data for school districts in Ontario. We use the data from 1978 because it is the most recent complete data set. For any given year the difference in the per pupil grants to the Public and RCSSB is virtually constant across districts. The RCSSB has received a larger per pupil grant throughout the entire history of public sector schooling in Ontario. Our model predicts that the more unequal the grants the greater the likelihood of the collusive agreement collapsing. We cannot test this prediction with the available data since the differences in the grants to the two boards do not differ across school districts enough to test the hypothesis.

Our data indicate that the fraction of Roman Catholic's varies considerably across school districts. One of the conclusions drawn in the previous section is that $y$, the fraction of students who are allowed to choose which school to attend, and the ease of student transfer between the systems will be an important determinant of the amount of slack in the school systems. We believe that a cross-section study of the behavior of the Ontario school boards provides an excellent opportunity to evaluate this prediction of our thesis. If our argument is correct we will observe more educational expenditures and less slack where $y$ is larger and we may infer that the effect of the Minister's extension of choice to a larger set is to reduce collusion.

Our analysis is organized as follows. First, we examine the behavior of the local school boards with respect to the level of expenditures on educational services that benefit the parents of school children. Second, we study the level of slack or "fat" in the budgets of the local boards. Finally, we review the history of the Minister's actions on the issues of the conditions to qualify as Roman Catholic for the purposes of schooling and on his refusal to alter the structure of the game. Casting the hypotheses described above in terms of the available data, we have three hypotheses derived from $h 3$ above, each of which will be discussed in detail below.

H1: Where the proportion of Roman Catholic's is higher there will be a greater incidence of kindergarten for four year olds, smaller class sizes, and more non-required transportation.

20 Obviously, by educational expenditures, we mean those over and above the expenditures necessary to provide the minimum education services mandated by the Minister. 
Our first hypothesis follows from the fact that collusion was less likely the larger was the fraction of students that could choose which school to attend: the Roman Catholics. Obviously, we are unable to observe the level of slack in any district. However, our model predicts that real educational expenditures, $e_{p}, e_{r}$, are larger in the absence of collusion. In other words, $e_{i}^{*}>e_{i}^{c}$ for $i=p, r$. It is very important to remember that $e_{i}$ represents the educational services, provided by the school which are direct benefits to the children attending (or their parents). Thus, since we can observe certain differences in expenditures for educational services, we will examine the effect of a change in the fraction of Roman Catholics in a school district on the level of these expenditures.

Our empirical tests are hampered by the fact that the Ministry mandates certain minimum levels of these educational expenditures. It also regulates the provision of transportation. In other words, the Ministry limits the scope of competition between the systems in the provision of educational services. In spite of this, the school boards are still able to compete through the provision of educational services. They have the option of offering kindergarten to four year olds, offering smaller classes, and/or offering some "enriched" programs. ${ }^{21}$ The boards are also permitted to provide more transportation services than are required by the Minister. Thus we expect to see more of all of these services in districts with a larger percentage of Roman Catholics, $y$.

However, before describing the tests of our hypotheses, we must provide some information about the data set that we use. In the empirical work that follows our sample consists of 56 elementary school boards in Ontario (27 RCSSB) with enrollments generally greater than 3,000 pupils. We do not run the regressions separately for each type of school board because collusion must be self-enforcing. This implies that if either of the boards has the incentive to "cheat" on the collusive agreement, competition will have been fostered.

Before proceeding, we provide a brief description of the data employed in the empirical work. The contested portion of the market for elementary school pupils is defined by the fraction of Roman Catholics, \%RC, in the school district. We use median income, Med $\mathrm{Y}$, as a proxy for the demand for educational services. It would correctly capture this demand if the median voter model of the provision of public services applied exactly. ${ }^{22}$ We include a system dummy, D (equals one for RCSSB and zero for Public), to capture any systemic regularity. Total enrollment, E, is included in the equation for class size to control for the effects of the lumpiness of teacher inputs. This effect may be important in the smaller school districts. Lastly, we include the grant weighting factor, $\mathrm{G} \mathrm{W}^{\prime} \mathrm{t}$, because provincial grants are awarded according to fiscal capacity relative to need. The Ministry establishes a basic grant per pupil for the lowest need board. For the remaining school boards the Ministry establishes a grant weighting factor which is multiplied by the basic grant to yield the per pupil grant to the respective school board. For the boards in our sample the grant weighting factor ranges from 1.023 to 1.152 .

Our first hypothesis is that different measures of educational services should be positively related to the variables that inhibit collusion. We regressed pupil teacher ratios (PTR) against the percent of Roman Catholic's (\%RC), as well as, median income (Med $Y$ ), the system dummy ( $D=1$ for RCSSB), the grant weighting factor $(G \mathrm{~W} t)$, and enrollment $(E)$. The results are reported in equation (R1). The coefficient for $\% \mathrm{RC}$ has the predicted sign and is significant at $90 \%{ }^{23}$ The other

21 These programs include cultural enrichment programs, art and music, and advanced courses.

22 There is some debate on this issue (see Romer and Rosenthal [1979]) but for our purposes this median voter model is adequate.

23 Note that whether smaller classes contribute to achievement is not important because parents perceive class size to be important in and of itself as has been reported in various Gallup Poll studies. 
variables are not generally significant except for $\mathrm{G} \mathrm{Wt}$. The latter result indicates the school boards use the increased grant to reduce class size which is consistent with the non-collusive outcome to the game.

$$
\begin{aligned}
& \mathrm{PTR}=38.934-2.351 \% \mathrm{RC}+0.000037 \mathrm{Med} \mathrm{Y}-0.494 \mathrm{D}-16.735 \mathrm{G} \mathrm{Wt}+0.000015 \mathrm{E} \\
& \begin{array}{llll}
(6.29) \quad(1.66) \quad(0.60) \quad(1.41) \quad(3.08)
\end{array} \\
& R^{2}=0.33 \\
& F_{5,50}=6.46
\end{aligned}
$$

where

$$
\begin{aligned}
\% \mathrm{RC} & =\text { the fraction that is Roman Catholic } \\
\text { Med } \mathrm{Y} & =\text { the median family income in the school district } \\
\mathrm{D} & =\text { dummy variable }: \mathrm{D}=1 \text { for RCSSB, } \mathrm{D}=0 \text { for Public } \\
\mathrm{GWt} & =\text { the grant weighting factor } \\
\mathrm{E} & =\text { the enrollment in the school board. }
\end{aligned}
$$

As we noted above, the board may provide more transportation services than are mandated by the Minister. This is usually done by offering transportation to pupils who live nearer to the school. In effect, this service is an additional educational expense that benefits the family not the bureaucrats. To see if this form of additional service was also more prevalent in the presence of those features that we believe are related to less collusive environments, we regressed transportation expenditure per pupil, T E/p, against \%RC, Med Y, D, and G Wt. The results, reported in equation $\mathrm{R} 2$, cannot reject the hypothesis. The coefficient on the \%RC term has the predicted sign, transport expenditure increases where the market is more contested, and it is significant at the $90 \%$ level.

$$
\begin{aligned}
& \mathrm{T} \mathrm{E} / \mathrm{p}=721.36+59.09 \% \mathrm{RC}-0.00521 \mathrm{Med} \mathrm{Y}+12.07 \mathrm{D}-490.53 \mathrm{G} \mathrm{W} \mathrm{t} \\
& R^{2}=0.152 \\
& F_{4,51}=3.45
\end{aligned}
$$

The dependent variable includes all transportation expenditure. School boards with a larger rural component are required to spend a larger amount on pupil transportation and this is reflected in their grant weighting factor. Rural areas tend to have lower income levels which explains the negative coefficient on the median income term.

Another educational service that the systems might offer is kindergarten for four year olds. An interesting and suggestive regularity is that the Public system only provides this service in areas where the RCSSB also offers it. The RCSSB provides kindergarten for four year olds significantly more frequently than the Public school board. One potential explanation for the RCSSB's behavior is that it causes an increase in their enrollment. Parents cannot determine their affiliation child by child. Thus, if the parents have several children and wish to send their four year old to kindergarten, then they must send their older children to the RCSSB as well. Since the RCSSB's Provincial grant per pupil is larger than the Public board's Provincial grant, then the RCSSB has a much greater incentive to "cheat" on a collusive agreement by offering this particular type of educational service.

To test the relation between the \%RC and the incidence of four year kindergarten we sorted our sample of boards by whether they offered kindergarten to four year olds or not. We then 
used a non-parametric Mann-Whitney test ${ }^{24}$ to test the hypothesis that boards with a higher fraction of Roman Catholic's would be more likely to offer this service. The test does not reject the hypothesis. The Z-statistic is 1.623 , significant at the $90 \%$ level. This lends support to our belief that the RCSSB utilizes four year kindergarten to compete with the local Public board when a larger fraction of the market is contested. ${ }^{25}$

Our second hypothesis is suggested from the direct observation that if the systems are colluding, they are "consuming" a larger amount of perquisites than they would otherwise consume. Because they are not able to take the benefits of collusion in a pecuniary form and because they refuse to tell us how much of their educational expenses really purchase perquisites, we focus on differentials in school revenues. Since the school boards must balance their budgets, focusing on revenues is equivalent to focusing on the schools' total expenditures. We believe that if we control for the other explanations for differences in expenditures, the remaining differences can be attributed to bureaucratic excesses. The other explanations for differences in expenditures are captured by our Grant Weighting Factor, G Wt, which adjusts for local tax base differences and local educational needs and median income. These needs include capital projects, French language classes, extraordinary transportation requirements in rural districts, and for other mandated services when their costs differ across districts. ${ }^{26}$

As our analysis suggested, if the real interest rate is less that $50 \%$, then increases in the proportion of Roman Catholic's, $y$, should make collusion less likely. Thus, we predict that the proportion of expenditure financed from local taxes will be smaller in districts with a larger fraction of Roman Catholic's. This follows because the Minister adjusts the local tax burden so that any additional services as well as additional slack must be funded by local taxes. The use of median income is designed to control for differences in local demand for educational services. Hence, any remaining differences ought to reflect differences in the level of slack in the budget. Thus, our second hypothesis is:

H2: The proportion of revenue financed from local taxes will be lower in those jurisdictions where the proportion of Roman Catholics is higher and the level of administrative expenditures will be higher.

In equation (R3) we have regressed the percentage of total expenditure financed from local taxation, NetE, on the fraction of Roman Catholics in the population of the district and other variables including Med Y. This variable has been included to control for the demand for educational services. Thus, we expect that the coefficient on \%RC will be negative and that the coefficient on Med $Y$ will be positive reflecting the fact that NetE must be higher so that the board can fund the provision of the additional educational services.

Our results show that the coefficient on \% $\mathrm{RC}$ is negative and significant at the $95 \%$ level and the coefficient on Med $\mathrm{Y}$ is positive and significant at the $99 \%$ level. Thus, our priors are consistent with our regression results. That is, our results do not reject $\mathrm{H} 2$ which suggests that the Minister

24 See Conover, 1982, pp 216-227 for details.

25 There is interesting anecdotal evidence to suggest that the Minister has also attempted to keep the school boards from engaging in too much rent seeking. Apparently; some RCSSB's attempted to extend regular kindergarten to full day. The Ministry refused to extend the grants to cover the additional cost.

26 Recall our discussion of this issue in the section on Institutions. 
is successfully creating a competitive environment.

$$
\begin{aligned}
& \mathrm{NetE}=-1.053-0.241 \% \mathrm{RC}+0.000019 \mathrm{Med} \mathrm{Y}-0.2591 \mathrm{D}+1.063 \mathrm{G} \mathrm{Wt} \\
& \text { (2.15) (2.01) } \\
& \text { (4.13) } \\
& \text { (8.81) (2.42) } \\
& R^{2}=0.704 \\
& F_{4,51}=34.18
\end{aligned}
$$

Another method of determining whether or not an increase in \% RC causes a decrease in the likelihood of collusion is to study its effect on the level of expenditures on administration, $A \$$. Again, we include G Wt and median income to control for differences in demand for educational services.

$$
\begin{aligned}
& \mathrm{A} S=0.017-0.0073 \% \mathrm{RC}+0.000025 \mathrm{Med} \mathrm{Y}+0.00975 \mathrm{D}+0.00796 \mathrm{G} \mathrm{W}^{\mathrm{t}} \\
& \text { (0.82) (1.45) } \\
& \text { (1.32) } \\
& R^{2}=0.549 \\
& F_{4,51}=17.74
\end{aligned}
$$

Finally, we have argued that there is a great deal of competition for the position of Minister. We have also argued that he has private incentives to reduce bureaucratic excesses and that these excesses are reduced by fostering an environment in which the systems behave non-cooperatively. Together, these features suggest that the Minister should be unwilling to succumb to pressure to change the environment such that the systems will find it easier to collude which is our third hypothesis.

H3: The Minister will maintain the structure of the game between the Roman Catholic schools and the Public schools despite pressure to reform it.

As a test of our third hypothesis we examine the Minister's response to the RCSSB's attempts to force a change in the design of the game. Recall that it is within the discretion of the Minister and the courts to alter the definition of 'Roman Catholic' for schooling purposes and to alter the method by which local property taxes are divided between the systems. The courts have ruled several times since 1900 on the issue of the RCSSB access to a portion of the taxes paid on commercial and industrial property owned by widely held corporations. In each case the rulings have affirmed the position taken by the Minister: in order to assign any portion of the tax payments to the RCSSB, the corporation must demonstrate that the appropriate fraction of its shareholders are Roman Catholic AND that they wish to have their taxes to go to the RCSSB. The corporation has little incentive to incur the transactions costs necessary to meet the Ministry requirement and the property taxes are almost universally paid to the Public. ${ }^{27}$ The precedent was set in Windsor Board of Education (Public) $v$ Ford Motor Company [1941]. This case arose because Ford paid part of its property tax to the Windsor RCSSB. The court ruled that Ford must prove that the fraction of its shareholders who were Roman Catholic was the same as the fraction of property tax payments allocated to the RCSSB.

Another possible change would be for the Minister to eliminate the differential in the Provincial (per pupil) grants to Public and RCSSB's. While the boards have petitioned for this, the Minister has not done so. We believe that our results suggesting that the differential plays an important

27 See Cameron [1972]. 
part in limiting the boards' ability to collude is a reasonable explanation for the Minister's decision. We also note in passing that the Minister has not established at mechanism to permit the Public and RCSSB to make side payments. ${ }^{28}$

It is also interesting to note that the Minister has worked to increase the fraction of the market that is contestable by relaxing the conditions necessary to qualify as Roman Catholic for the purposes of school choice. ${ }^{29}$ Perhaps most significant is the fact that the Minister has increased the volume of the grants to the RCSSB enabling it to equate its local tax rate to the Public's. Prior to the early 1970's the RCSSB was compelled to set its rate several points above that of the Public to cover deficiencies in the grant from the Province. Conceivably such a premium may have discouraged some Roman Catholic's from sending their children to the RCSSB. The action of the Minister coincided with an expansion of the share of elementary school enrollment in the RCSSB. From 1960 through 1980 this share increased from approximately twenty-five to thirtyfive percent. ${ }^{30}$ Notice that the coincident expansion of the grants to the RCSSB is consistent with encouraging a competitive environment [McKee, 1987a].

The empirical evidence in this section is quite strong in support of the general hypothesis of the existence of competition between the Public and the RCSSB in each school district. There is some further anecdotal evidence of this competition. In an interview, an official of the Ottawa RCSSB informed us that they periodically search the property assessment roll and send letters to Roman Catholic's who are listed as Public School supporters. These letters inform the recipient of the fact that RCSSB mill rates are identical to those of the Public and that the RCSSB needs the support of all Roman Catholic's. This is the sort of overt action usually described in the texts as indicative of the collapse of the cartel. The behavior concerning four year kindergarten is also indicative of overt defection from the cartel.

We note that our results do not and cannot determine whether the allocation of resources in Ontario public schools is that which would obtain under perfect competition and private supply. The equilibrium we observe is behaviorally competitive in the sense that it is non-cooperative. That is, the tax levels are lower than would obtain under collusion but are not necessarily as low as they would be if the boards' actions could be fully monitored, costlessly.

\footnotetext{
28 Having one of the board's provide a certain service and sharing the costs would be a reasonable mechanism that would, without significant monitoring, allow the boards to engage in direct side payments.

29 See Fleming, [1971b].

30 See Education Statistics, Ministry of Education, Toronto, Canada (various years).
} 


\section{Comelusions}

The political sponsor of a public sector bureau has an incentive to promote competition between bureaus whenever possible. If the Minister faces two or more bureaus providing the same service and the clientele is mobile, then the Minister fosters competition between bureaus thereby reducing their ability to collude. The bureaus will collude, where possible, to raise taxes and/or to lower productive expenditure (effort). The combined effect is to increase the perquisites available by increasing the slack in the bureau's budget.

In this paper we have provided a great deal of evidence which suggests that the Minister of Education in Ontario has designed a mechanism, constructed a "game" between the RCSSB and the Public, in such a manner as to encourage the non-cooperative outcome. The results are lower taxes and higher productive expenditure where the market is more contested, i.e, in districts with more Roman Catholic's.

The Minister has maintained the structure of the game despite pressure from the RCSSB and supporters to increase the availability of the local tax base to the RCSSB. Where the Minister has extended resources to the RCSSB, in recognition of its growing political power, the extension has come through increased grants and, ultimately, extension of public funding through secondary schooling. ${ }^{31}$ Both of these responses have maintained the pressure on the collusive outcome to the game. In fact, the extension to secondary schooling has expanded the scope of the game.

We expect that our argument is general and that examination of other instances of parallel public sector bureaus under a single political sponsor would yield similar results. Since there are potentially many such cases, our argument and its empirical implications is an important extension of the traditional public choice analysis of public sector bureaus.

31 The RCSSB was granted public funding to extend its provision of educational services to secondary school aged children heginning in the $1986 / 87$ school year. 


\section{References}

Abreu, D., Repeated Games with Discounting, Ph. D Dissertation, Department of Economics, Princeton University, 1983.

Borcherding, T. E., "Toward a Positive Theory of Public Sector Arrangements", in Canadian Crown Corporations, Prichard, R., (ed.), Buttersworth, Toronto, Canada 1983.

Breton, A., and R. Wintrobe, The Logic of Bureaucratic Conduct, Cambridge University Press, New York, 1982.

Breton, A., and R. Wintrobe, "The Bureaucracy of Murder, Revisited," Journal of Political Economy, 1986.

Cameron, D., Schools for Ontario: Policy-Making, Administration, and Finance in the 1960's, University of Toronto Press, Toronto, Canada, 1972.

Education Act, Ontario [1974;, Queen's Printer, Toronto, Canada, 1984.

Education Statistics, Ministry of Education, Toronto, and Ontario, 1960-1985.

Fleming, W' G., Ontario's Educative Society, University of Toronto Press, Toronto, Canada, 1971.

Fleming: W. G., The Administrative Structure, vol. 2, University of Toronto Press, Toronto, Canada, 1971b.

Friedman, J., "A Non-cooperative Equilibrium for Supergames," Review of Economics Studies, vol. 38, 1971.

Green, E., and R. Porter, "Noncooperative Collusion Under Imperfect Price Information," Econometrica, January, 1984.

Mchee, M., "Political Competition and the Roman Catholic Schools: Ontario, Canada," Public Choice, $1987 \mathrm{a}$.

McKee, M., "In Networks We Trust: All Others Pay Cash," European Journal of Political Economy. $1987 \mathrm{~b}$.

McKee, M., and R. Wintrobe, "The Decline of Organizations and the Rise of Administrators: Parkinson's Law in Theory and Practice," University of Western Ontario, 1987.

Niskanen, W. A., Bureaucracy and Representative Government, Aldine, Chicago, Illinois, 1971.

Niskanen, W. A., "Bureaucrats and Politicians," Journal of Law and Economics, vol. 18. no. 3. 1975.

Prichard, J. R. S. (ed), Crown Corporations: The Calculus of Choice, Buttersworth, Toronto, Canada, 1983.

Segerstrom, P., "Demons and Repentance," working paper, Michigan State University, 1985a.

Segerstrom, P., "Symmetric and Asymmetric Punishments in the Theory of Noncooperative Collusion," working paper, Michigan State University, October, $1985 \mathrm{~b}$. 


\section{Recent CREST Working Papers}

87-1: Jeffrey K. MacKie-Mason, "Nonlinear Taxation of Risky Assets and Investment, With Application to Mining" September, 1984.

87-2: Jeffrey K. MacKie-Mason, "Sequential Decision Problems and Asymmetric Information" September, 1985.

87-3: Michelle J. White, "Contract Breach and Contract Discharge due to Impossibility: A Unified Theory" July 29, 1987.

87-4: Ted Bergstrom, “Systems of Benevolent Utility Interdependence” May 19, 1987.

87-5: Ted Bergstrom, “A Fresh Look at the Rotten Kid Theorem-and Other Household Mysteries" November, 1986.

87-6: Michelle J. White, “The Corporate Bankruptcy Decision” July, 1987.

87-7: Michelle J. White, "Location Choice and Commuting Behavior in Cities with Decentralized Employment" July, 1987.

87-8: Lawrence E. Blume and David Easley, "Implementation of Walrasian Expectations Equilibria" December, 1985.

87-9: Lawrence E. Blume, "Lexiocographic Refinements of Nash Equilibrium" April, 1986.

87-10: David Lam, "Lorenz Curves, Inequality, and Social Welfare Under Changing Population Composition" June 16, 1987.

87-11: Mark Bagnoli and Naveen Khanna, "Equilibrium with Debt and Equity Financing of New Projects: Why More Equity Financing Occurs When Stock Prices are High" June, 1987.

87-12: Mark Bagnoli and Barton L. Lipman, "Provision of Public Goods: Fully Implementing the Core through Private Contributions" March, 1987.

87-13: Mark Bagnoli and Barton L. Lipman, "Successful Takeovers without Exclusion" August, 1987.

87-14: Mark Bagnoli and Michael McKee, "Controlling the Game: Political Sponsors and Bureaus" May, 1987.

87-15: Mark Bagnoli and Michael McKee, "Can the Private Provision of Public Goods be Efficient?-Some Experimental Evidence" March, 1987.

87-16: Mark Bagnoli, "Non-Market Clearing Prices in a Dynamic Oligopoly with Incomplete Information" January, 1986.

87-17: John Laitner, "Bequests, Gifts, and Social Security” February 28, 1986.

87-18: John Laitner, "Dynamic Determinacy and the Existence of Sunspot Equilibria" May 12, 1986.

87-19: David Lam, “Does a Uniform Age Distribution Minimize Lifetime Wages?” August 12, 1987.

87-20: David Lam, “Assortative Mating with Household Public Goods" April, 1987.

87-21: Jeffrey A. Miron and Stephen P. Zeldes, "Production, Sales, and the Change in Inventories: An Identity that Doesn't Add Up" June 1987.

87-22: Jeffrey A. Miron and Stephen P. Zeldes, "Seasonality, Cost Shocks, and the Production Smoothing Model of Inventories" December, 1986.

87-23: Hal R. Varian, "Differences of Opinion in Financial Markets" March, 1985.

87-24: Roger H. Gordon and Hal R. Varian, "Taxation of Asset Income in the Presence of a World Securities Market" August, 1986. 
87-25: Hal R. Varian, "Measuring the Deadweight Costs of DUP and Rent Seeking Activities" November, 1982.

87-26: Hal R. Varian, "Price Discrimination” January, 1987.

87-27: Roger H. Gordon and Hal R. Varian, "Intergenerational Risk Sharing" October, 1985.

87-28: Hal R. Varian, "Three Papers on Revealed Preference" August, 1987.

87-29: Hal R. Varian, “Optimal Tariffs and Financial Asséts” April, 1987.

87-30: Jonathan Cave and Stephen W. Salant, "Cartels That Vote: Agricultural Marketing Boards and Induced Voting Behavior" August, 1987.

87-31: Stephen W. Salant and Donald H. Negri, "Pastures of Plenty: When is the Standard Analysis of Common Property Extraction Under Free Access Incorrect?” July 10, 1987.

87-32: Stephen W. Salant, "When is Inducing Self-Selection Sub- optimal for a Monopolist?" Fébruary, 1987.

87-33: Stephen W. Salant, "Treble Damage Awards in Private Lawsuits for Price-Fixing" August, 1987.

87-34: Stephen W. Salant and Roy Danchick, "Air Force Academy Attrition: A New Perspective on the College Dropout Problem" August, 1987.

87-35: Stephen W. Salant and Eban Goodstein, "Committee Voting Under Alternative Procedures and Preferences: An Experimental Analysis” April 20, 1987.

87-36: Robert B. Barsky and Jeffrey A. Miron, "The Seasonal Cycle and the Business Cycle" June, 1987.

87-37: Robert B. Barsky, N. Gregory Mankiw, Jeffrey A. Miron and David N. Weil, "The Worldwide Change in the Behavior of Interest Rates and Prices in 1914" July, 1987.

87-38: Jeffrey K. MacKie-Mason, "Taxes, Information and Corporate Financing Choices" April 1986. 



\begin{tabular}{ll} 
MichU & Bagnoli, Mark \\
DeptE & McKee, Michael \\
CenREST & Controlling the Game \\
\hline A WHOR & Political Sponsors and \\
$87-14$ & Bureaus \\
\hline TITLE & \\
\hline \hline
\end{tabular}

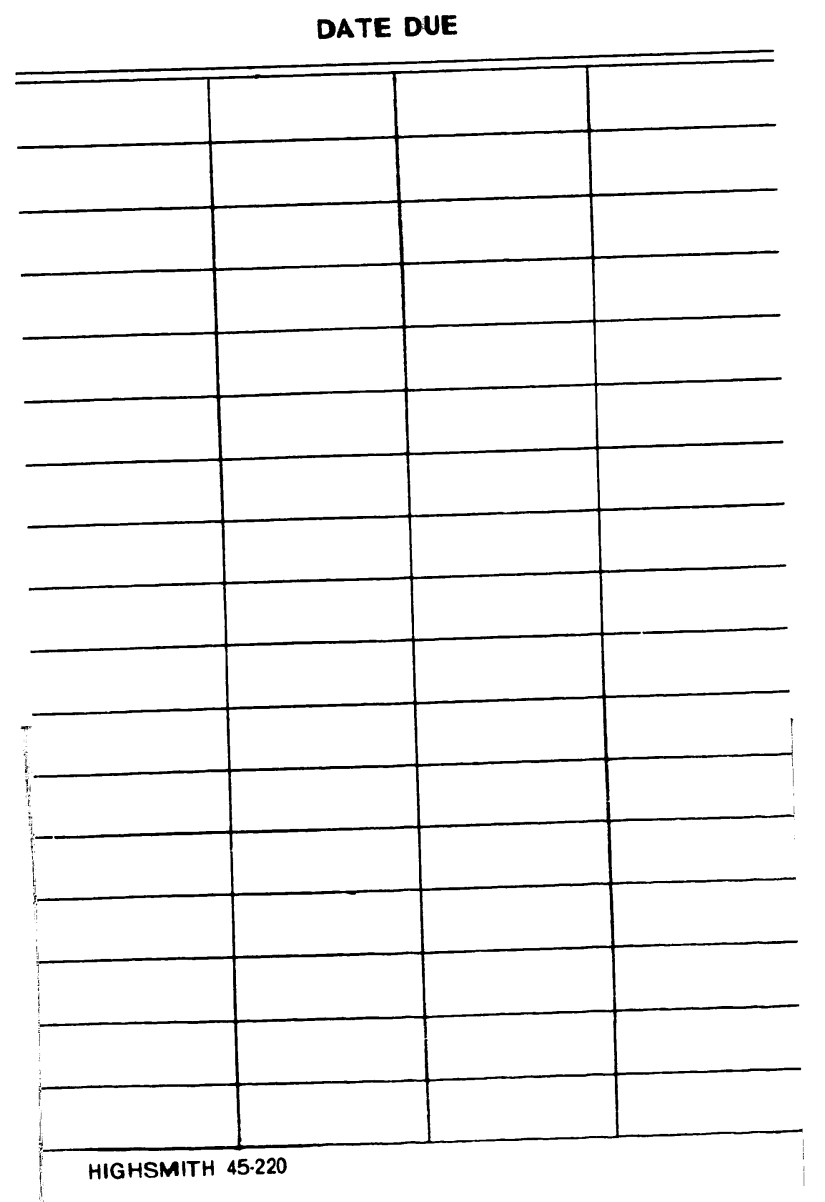


